\title{
REPENSANDO ESTRATÉGIAS DE ENSINO NO PROCESSO DE APRENDIZAGEM
}

\author{
Jeanne Marie R. Stacciarini* \\ Elizabeth Esperidião**
}

STACCIARINI, J.M.R.; ESPERIDIÃO, E. Repensando estratégias de ensino no processo de aprendizagem. Rev.latinoam.enfermagem, Ribeirão Preto, v. 7, n. 5, p. 59-66, dezembro 1999.

Trata-se de uma pesquisa qualitativa que procurou obter opiniões acerca do processo de aprendizagem a que foram submetidos os participantes de uma oficina de vivência "Conhecendo o SER Enfermeiro", oferecida no $47^{\circ}$ Congresso Brasileiro de Enfermagem, na cidade de Goiânia, em 1995. Constituímos como objetivo: analisar as estratégias de ensino implementadas durante as vivências propostas na oficina. A coleta de dados foi realizada através de uma ficha de avaliação, respondida pelos sujeitos deste estudo, todos integrantes da oficina. Submetemos as respostas descritas a uma análise de conteúdo, utilizando a categorização temática, que permitiu identificar categorias que salientam elou ressaltam as estratégias recorridas.

UNITERMOS: aprendizagem, enfermagem

\section{APRESENTAÇÃO}

O exercício da docência no curso de graduação em enfermagem possibilita-nos questionar a metodologia no processo ensino-aprendizagem, que vem sendo implementada tanto na academia como nos programas de aperfeiçoamento e atualização dos profissionais e nos eventos dirigidos à categoria.

A prática diária sinaliza a ocorrência de um ensino centrado na figura do professor, que detêm a autonomia do conhecimento, gerando estratégias repetitivas, geralmente com aulas expositivas, e conseqüentemente criando um fluxo unilateral de comunicação, dificultando o desenvolvimento do pensamento crítico por parte do aprendiz, que na maioria das vezes assimila o que lhe é imposto, sem muitos questionamentos.

Esta conduta caracteriza o ensino tradicional, supondo que o indivíduo que aprende é incapaz de ter controle de si mesmo, devendo ser conduzido por pessoas que sabem mais que do ele. Este tipo de educação freqüentemente impede, a criatividade, a iniciativa, a auto-responsabilidade e a auto-direção. Freire apud HADDAD et al. (1993), denomina esta prática de educação bancária, onde o papel do aluno é limitado a receber depósitos, guardar e arquivar, preocupando-se basicamente com a transmissão do conhecimento e com a experiência do professor, sem atentar para os aprendizes enquanto pessoas que fazem parte de um contexto maior.
Assim, gera-se um aluno passivo, memorizador de conceitos abstratos e sem preparo para resolver questões práticas, fundamentadas na realidade em que vive.

É sabido que a comunicação não se efetiva em mão única, mas tem um caráter interativo, com ação recíproca, e no entanto, parece que o processo ensinoaprendizagem implementado nas instituições de ensino do Brasil continua pautado num fluxo unidirecional, ou seja, o docente enquanto repassador e o aluno como receptor do conhecimento.

Não temos dúvida de que, pela própria formação, o educador é possivelmente o maior conhecedor do assunto, mas por outro lado, questionamos se esta forma de ensinar é a mais adequada.

A experiência decorrente do fazer cotidiano do professor constitui um saber pedagógico, que deve ser valorizado, e mais do que isso, utilizado a serviço de estratégias de ensino que proporcionarão ações transformadoras e não ações estagnantes, como ocorre freqüentemente.

Admitindo o conhecimento como algo inacabado e processual, não se pode compreender o ensino como uma seqüência de ações padronizadas com finalidade de transmitir informações, caracterizando-o como simples processo de disseminação de informações a respeito de um conteúdo fixo e distribuído ao longo do tempo, conforme contesta TOREZAN (1994). Afirma ainda, que esta concepção de ensino sugere que os educadores não apreendem plenamente o papel mediador que

\footnotetext{
* Enfermeira, docente da Faculdade de Enfermagem da Universidade Federal de Goiás, Doutoranda em Psicologia na UNB

** Enfermeira e Psicóloga, docente da Faculdade de Enfermagem da Universidade Federal de Goiás
} 
desempenham na construção de conhecimento do aprendiz.

A postura dos educadores, de um modo geral, no seu fazer pedagógico, requer uma auto-avaliação no que se refere à ação em termos de sua propriedade e adequação aos fins educacionais, no sentido de assumir a mediação do conhecimento de modo a ser partilhado na relação que estabelece com o aluno, e não centrado na figura do professor.

HADDAD et al. (1993) consideram que ensinar é facilitar a aprendizagem, criando condições para que o outro, a partir dele próprio aprenda e cresça. Acrescentam que, nesta modalidade de ensino, o indivíduo é o centro da aprendizagem que se processa em função do desenvolvimento e interesse do aluno. Coloca-se assim uma ênfase nas relações interpessoais e no crescimento pessoal que delas resultam.

Não podemos desconsiderar que o processo de aprendizagem em si encontra-se atrelado a outros fatores. Neste sentido, BRANT \& ANTUNES (1995) afirmam que apesar de já existir na enfermagem a semente de uma proposta transformadora, advertem que os enfermeiros continuam buscando a competência técnica e o reconhecimento de seu espaço social sem a compreensão exata dos determinantes de sua prática.

Ao longo do tempo, através da docência, temos tido oportunidade de observar que a formação acadêmica do enfermeiro passa indubitavelmente, entre outras, por questões de natureza filosófica e pedagógica incorporadas no currículo, norteando a atuação do profissional.

Estudos feitos por VENDRÚSCOLO \& MANZOLLI (1996) apontam que há tendências no currículo de enfermagem que apreendem diferentes formas de conceber o mundo, a sociedade, o homem, a saúde, e ainda os métodos e processos educacionais, resultando portanto em diferentes formas de agir do profissional. Ressaltam, a partir de outras citações, que o professor irá influenciar o processo educacional de acordo com sua ótica particular, condicionada pela maneira como ele vê e sente o mundo. Assim, a ação educativa será traduzida ora por posturas individualistas ou conservadoras, ora através de posições sociais ou de renovação, sempre de acordo com a atitude individual do professor (Yamoto \& Romeu apud VENDRÚSCOLO \& MANZOLLI, 1996).

Algumas tentativas de inovação nas estratégias de ensino decorrem mais pela visão e compromisso do próprio educador ou de um grupo deles que defendem um ensino crítico e libertador, do que pela estrutura, pela política educacional ou fundamentação filosófica acerca do perfil profissional que a instituição pretende formar. Por outro lado, ALMEIDA (1992), investigando sobre as tendências pedagógicas utilizadas pelos docentes paraibanos, na graduação em enfermagem, deduz que apesar dos currículos e planos de enfermagem continuarem tradicionais, os professores estão avançando em direção a uma prática mais coerente com a realidade atual.

Neste final de século, com os valores sendo repensados e as transformações ocorrendo vertiginosamente, não é possível manter os moldes tradicionais de ensino, pois estes deixam de corresponder às necessidades atuais do educando. Tendo-se em vista prepará-lo para atuar no mundo em transformação, é preciso considerar o desenvolvimento da capacidade de análise e crítica das pessoas, a fim de instrumentalizar o processo de mudança interior de cada um.

Em relação à enfermagem, há necessidade de enfatizar esta premissa, considerando o papel de liderança que o enfermeiro tem assumido, tanto junto à equipe de enfermagem, na equipe multiprofissional, como nos três níveis de gestão da saúde pública, onde sua atuação tem sido cada vez mais evidente.

Da mesma forma, é inegável a influência que o cenário sócio-político exerce sobre o ensino, no âmbito das políticas educacionais e na própria relação entre as pessoas envolvidas, especialmente no relacionamento professor-aluno, influência esta que pode ser considerada como fundamental no processo ensino-aprendizagem.

CHAVES (1993) afirma que a sociedade, avaliando e redimensionando seus valores, redefine conceitos e papéis sociais que se manifestam na esfera da educação, modificando a característica das relações pautadas em papéis de docente/discente, conseqüentemente alterando a qualidade do processo ensino-aprendizagem.

O momento histórico e social em que vivemos exige do profissional um perfil mais crítico, arrojado e perspicaz. Temos observado que os enfermeiros estão sendo colocados no mercado de trabalho, despreparados, não tanto na dimensão técnica, mas o que consideramos mais agravante, no sentido do pensamento crítico.

Enquanto formadores de recursos humanos, devemos nos preocupar mais com o como ao invés do que ensinar, sem esquecer naturalmente dos objetivos educacionais, ou seja do porquê ensinar. Não se pretende minimizar a importância do conteúdo programático em função da didática ou dos métodos de ensino utilizados; o que se insinua é que o modo de transmitir pode despertar ou elevar o grau de interesse e participação do aluno em relação ao que se propõe.

Assim, como ressalta LIBÂNEO $(1985,1991)$, faz-se necessário resgatar os conteúdos no processo de ensino, como forma de instrumentalização dos educandos, tendo em vista o exercício da cidadania. Assim, o conteúdo deixa de ser um fim em si mesmo, constituindose em um meio de transformação social.

$\mathrm{Na}$ enfermagem, existem iniciativas de 
professores, demostrando preocupação com os métodos de ensino, mas geralmente são tentativas isoladas e causam pouco impacto, cujas mudanças tem se processado a passos muito lentos em relação às grandes transformações pelas quais estamos passando.

O saber deve ser construído sob forma processual, onde professor e aluno assumam posições diferentes, mas que ocupem o mesmo nível na relação instituída, ou seja, juntos possam produzir o conhecimento. Assim, neste processo de construção não se pode negligenciar a experiência vivida por ambos. Concordamos com CHAVES (1993) quando fundamenta o processo ensino-aprendizagem nas relações interpessoais, que pode ser enriquecido ou não, de acordo com os papéis sociais entre os envolvidos, sendo aceitos e desempenhados com conformismo e passividade ou com visão reflexiva e crítica através de ações inovadoras.

BOCCHI et al. (1996) fazem considerações acerca da função do professor, do aluno e do relacionamento entre eles, defendendo as estratégias de ensino com abordagem humanística. O professor cria condições facilitadoras para que o aluno aprenda, estimula sua curiosidade encorajando-o a escolher seus próprios interesses, desde que seja auto-disciplinado, responsável por suas opções e crítico diante das problemáticas do futuro; oportuniza também sua participação ativa na formação e construção do programa de ensino do qual faz parte. O aluno, por sua vez, é respeitado "como pessoa" no processo contínuo de auto-realização com o uso pleno de suas potencialidades e capacidades. Assim, a relação decorrente entre eles tende a ser de autenticidade e congruência, o que provavelmente facilita o processo ensino-aprendizagem.

Estas concepções ressaltam o ensino como construção do conhecimento, através de experiências pessoais, no conjunto "de vir a ser" da pessoa humana.

A nossa proposta é centrar a metodologia na relação professor/aluno, onde cada um é considerado com suas bagagens e potencialidades e devem estar envolvidos em todo o processo, para que a aprendizagem ocorra sob um clima autêntico, permeável a trocas e propício ao desenvolvimento da capacidade de análise e crítica acerca do contexto sócio político no qual a saúde está inserida.

Desta forma, entendemos que o docente deve buscar novas estratégias de ensino, que extrapolam o simples repassar de conhecimento, despertando uma consciência crítica no aluno, que possivelmente ajudará a alicerçar uma nova enfermagem. Para tanto, acreditamos que a formação do profissional deve privilegiar situações de aprendizagem concedendo atitudes criativas, críticas e transformadoras.

ISAACS (1994) afirma que o educador de enfermagem deve refletir sobre aspectos que visam desenvolver o pensamento crítico dos alunos, com o propósito de também promover a liderança em enfermagem. Enfatiza que o processo dinâmico de perguntar, de raciocinar, de questionar os postulados prontos, contribuem no desenvolvimento da forma de pensar. Assinala ainda, a existência de esquemas tradicionais de ensino na maioria dos programas básicos de enfermagem (Vilallobos apud ISAACS, 1994). Finalmente, defende que deve-se incluir meios de desenvolver o pensamento crítico como parte integral na formação do enfermeiro, para que possa repercutir diretamente na sua liderança.

Nesse entendimento, enquanto educadoras que somos, temos desenvolvido práticas alternativas de ensino nas disciplinas sob nossa responsabilidade, na graduação em enfermagem e ainda em cursos de aprimoramento que oferecemos nos eventos científicos voltados à enfermagem. Nossa proposta é utilizar algumas estratégias didáticas que buscam capacitar o aluno sobre a temática em questão, a partir de seu mundo pessoal, enriquecendo seu trabalho, mesmo enquanto acadêmicos de enfermagem.

$\mathrm{Na}$ área da saúde mental, na qual estamos inseridas, temos procurado ir além do processo de ensinamento de habilidades teóricas e técnicas, proporcionando momentos de reflexão sobre o papel do enfermeiro, dentro de uma contextualização do seu processo de trabalho a partir da auto-percepção pessoal.

Embora várias autoras (PEPLAU,1952; TRAVELBEE, 1979; IRVING,1979; MANZOLLI, 1996) afirmem a importância do enfermeiro pesquisar e conhecer suas próprias motivações, emoções e seus impactos sobre os outros, a enfermagem parece ainda não admitir a necessidade do auto-conhecimento como fator essencial para as relações a serem desenvolvidas.

Pensamos que o papel do enfermeiro poderá ser melhor construído se emergir de uma conscientização sobre o Ser pessoa que reside no Ser profissional: suas potencialidades, desejos, temores e esperanças. O Ser enfermeiro está em constante interação consigo próprio e com o mundo; desta forma, defendemos que o lado humano do profissional precisa ser compreendido e valorizado.

Observamos no entanto, que o ensino na grande maioria dos cursos acadêmicos brasileiros privilegia a formação técnica, esquecendo-se de que o Ser "profissional" tem características inerentes ao Ser humano e nem sempre exploradas.

A partir destas concepções, programamos uma oficina de vivência intitulada "Conhecendo o SER Enfermeiro", que visava fundamentalmente despertar a valorização da pessoa humana (Ser) do enfermeiro. Foi desenvolvida através de técnicas facilitadoras de dinâmicas de grupo, de acordo com o programa e seus objetivos explícitos, e com o andamento dos trabalhos 
planejados. No decorrer desta, vislumbramos além de atender a finalidade específica do ensino, avaliar as estratégias empreendidas no decorrer da oficina. Desta forma, constituímos como objetivo: analisar as estratégias de ensino implementadas durante uma oficina de vivência, a partir de registros dos participantes.

\section{TRAJETÓRIA METODOLÓGICA}

Trata-se de um estudo qualitativo com análise descritiva, realizado no decorrer de uma oficina de vivência "Conhecendo o SER Enfermeiro", oferecida no $47^{\circ}$ Congresso Brasileiro de Enfermagem, na cidade de Goiânia, em 1995.

Pela especificidade dos trabalhos a serem empreendidos, oferecemos quinze vagas que foram preenchidas por enfermeiros, técnicos e acadêmicos de enfermagem oriundos de várias partes do Brasil (Brasília, Goiás, São Paulo, Paraná, Tocantins e Minas Gerais), com duração de dois dias, num total de seis horas.

Dos inscritos, dois indivíduos não compareceram, totalizando treze participantes da oficina, os quais foram sujeitos deste estudo.

Visamos substancialmente sensibilizar os integrantes acerca do auto-conhecimento, mobilizandoos enquanto Ser pessoa, destacando sua importância no processo de relação interpessoal. Tal sensibilização tornou-se possível a partir das reflexões que emergiam dos participantes durante os exercícios e/ou técnicas de grupo vivenciadas, cujas finalidades específicas tinham pertinência com os conteúdos propostos pela oficina, e que na íntegra direcionavam-se aos seus objetivos gerais. As estratégias de ensino utilizadas foram selecionadas através de indicações de ANTUNES (1995); YOZO (1995) e MIRANDA (1996) para situações semelhantes e coordenadas pelos pesquisadores.

As atividades do dia eram iniciadas por momentos de descontração, que consideramos como fase de aquecimento; nesta, propúnhamos alguns jogos, que além de preparar cada participante para as discussões, favoreciam o contato consigo mesmo e oportunizavam um ambiente harmônico necessário para a continuidade das vivências.

Seguidamente, os exercícios oferecidos, ora individuais, ora em grupo visavam incentivar a expressão do Ser pessoa contido no profissional: características e qualidades próprias (como cada um se percebe), e como estas influem nas suas relações interpessoais. Buscavam também estabelecer relação entre as características apontadas pelo grupo com as exigidas para o exercício profissional. Todos estes momentos eram permeados de reflexão téorica embasada nos conteúdos expressos, através das dinâmicas experienciadas pelos participantes e/ou observadas pelos coordenadores, que facilitavam as discussões.

Como término das vivências havia uma sessão de relaxamento, acompanhada de música, cujo objetivo era proporcionar o contato intrapessoal, naquele momento, assim como preparar o grupo para o retorno de suas atividades pessoais e profissionais.

Escolhemos como local uma sala de dramatização na Faculdade de Enfermagem da Universidade Federal de Goiás, cujo ambiente é propício ao tipo de vivências programadas.

A coleta de dados foi realizada através de uma ficha de avaliação, respondida pelos participantes, no final da oficina, que investigava sobre a experiência vivida. Garantimos o anonimato, orientando que não haveria necessidade de identificação; verificamos a possibilidade de utilizar as respostas para fins de pesquisa, situação aceita por todos.

O instrumento foi constituído por quatro questões abertas, sendo que três delas versavam sobre as estratégias de ensino vivenciadas, investigando as mais significativas para cada um, as maiores dificuldades encontradas e a contribuição proporcionada pelo evento; uma questão buscava sugestões para o aprimoramento da oficina em si (Anexo 1).

Para analisar o processo metodológico implementado, as respostas foram submetidas a uma análise de conteúdo. Cabe ressaltar que não foi analisado o assunto específico aprendido, e sim como a proposta didática foi recebida.

\section{ANÁLISE DE DADOS}

A partir das respostas descritas na ficha de avaliação, realizamos uma análise de conteúdo, criando categorias emergidas da descrição dos registros dos participantes. Segundo BARDIN (1977) as categorias são rubricas ou classes, as quais reúnem um grupo sob um título genérico, agrupamento efetuado em razão dos caracteres comuns destes elementos. No caso, optamos por uma categorização temática.

Restringir-nos-emos a descrever e analisar qualitativamente estas categorias, sem nos deter aos dados quantitativos. Esta análise ocorreu separadamente para cada questão, devido à especificidade de cada uma.

A seguir, apresentamos um quadro ilustrativo (Quadro1), com todas as categorias constituídas. Posteriormente, utilizando a ordem das questões da ficha de avaliação, as categorias são definidas e acompanhadas de alguns exemplos, que servem como "flashes", para demonstrar o processo desenvolvido. 
Quadro 1 - Questões investigadas e categorias encontradas através da ficha de avaliação da oficina de vivência “Conhecendo o SER enfermeiro". Goiânia, 1995

\begin{tabular}{|c|c|c|c|c|c|c|}
\hline \multirow{2}{*}{\multicolumn{2}{|c|}{$\begin{array}{l}\text { QUESTÕES } \\
\text { EXPERIÊNCLA MAIS } \\
\text { SIGNIFICATIVA }\end{array}$}} & \multicolumn{5}{|c|}{ CATEGORIAS ENCONTRADAS } \\
\hline & & $\begin{array}{c}\text { Relacao pessa } \\
\text { enfermeir. }\end{array}$ & Vivencia & $\begin{array}{c}\text { Vivência } \\
\text { individual*** }\end{array}$ & $\begin{array}{c}\text { Técricas } \\
\text { experienciadas*** }\end{array}$ & Descobertas \\
\hline \multirow{2}{*}{$\begin{array}{l}\text { DIFICULDADE DE } \\
\text { EXPRESSÃO DLANTE } \\
\text { DO TRABALHO } \\
\text { PROPOSTO }\end{array}$} & SIM & $\begin{array}{c}\text { Características } \\
\text { pessodis }\end{array}$ & $\begin{array}{l}\text { Exercícios } \\
\text { reflexivos**** }\end{array}$ & $\begin{array}{c}\text { Tipos de } \\
\text { experimentos } * * * *\end{array}$ & $\begin{array}{l}\text { Questões } \\
\text { situacionais }\end{array}$ & \\
\hline & Não & Jdentificasao & $\begin{array}{c}\text { Estratégias } \\
\text { de ensino } \\
* * * *\end{array}$ & & & \\
\hline \multicolumn{2}{|l|}{$\begin{array}{l}\text { CONTRIBUIÇÕES DA } \\
\text { OFICINA }\end{array}$} & $\begin{array}{l}\text { Processo } \\
\text { avaliativo }\end{array}$ & Intensidade & Enfermeiro & Resultados & \\
\hline \multicolumn{2}{|l|}{ SUGESTÕES } & $\begin{array}{l}\text { Significância da } \\
\text { experiência }\end{array}$ & $\begin{array}{l}\text { Continui- } \\
\text { dade**** }\end{array}$ & Estruturação*** & & \\
\hline
\end{tabular}

Ubs: ${ }^{\star \pi}$ : categorias que relacionam as estrategias metodologicas

sombreados: salientam categorias que estão vinculadas

Diante da primeira questão que investigava a experiência mais significativa vivenciada pelo sujeito, no decorrer da oficina, formamos como categorias:

Relação Pessoa-Enfermeiro - os conteúdos apreendem manifestações dos sujeitos, referentes à necessidade de integração do lado pessoal com o lado profissional. Parece que tinham a percepção de que estes aspectos funcionavam separadamente, como se isso fosse possível. Exemplos: "minha pessoa com o Ser enfermeiro", "não podemos separar o Ser enfermeiro da minha pessoa".

Vivência Grupal - as descrições enfatizam a experiência de trabalhar em grupo como algo significativo, importante para o processo de conhecimento e aprendizado dos participantes. Exemplos: "aprendi ouvindo cada um", "experiência de relacionar".

Vivência Individual - as manifestações sugerem uma contribuição do trabalho para o enriquecimento pessoal. Exemplos: "experiência de parar e pensar na pessoa que sou”, "pude sentir quanta riqueza existe dentro da gente".

Técnicas Experienciadas - posicionamentos em relação às técnicas que foram implementadas, ora considerando como algo difícil e às vezes acontecendo naturalmente. Exemplos: "fisicamente é bem mais dificil", "nessa oficina eu consegui relaxar, movimentar livremente...".

Descobertas - expressam o valor da experiência como forma de descobrimento de algumas características pessoais que pareciam não serem percebidas anteriormente. Exemplos: "antes o poder era invisivel", "adorei os resultados".

Os conteúdos sobre as dificuldades de expressão diante dos trabalhos propostos, foram divididos em duas partes. Agrupamos as repostas afirmativas, ou seja os sujeitos que manifestaram algumas dificuldades, e outro grupo para aqueles que não tiveram problemas na concretização das tarefas propostas.

As categorias para os indivíduos que afirmaram encontrarem dificuldades foram:

Características Pessoais - os relatos justificam as dificuldades relacionando-as com a forma de ser do sujeito. Exemplos: "tenho grande dificuldade em me expressar", "sou uma pessoa muito tímida".

Exercícios Reflexivos - afirmam que as dificuldades foram decorrentes do tipo de trabalho oferecido durante a oficina, visto que os exercícios requeriam certa introjeção. Exemplos: "tive que fazer um trabalho de auto-percepção durante todo o tempo", "tive que me forçar a fazer uma auto-reflexão".

Tipos de Experimentos - ressaltam algumas atividades específicas, considerando-as difíceis de serem executadas. Exemplos: "foi dificil de sentir roseira", "a dança não foi muito fácil".

Questões Situacionais - apontam os momentos de vida que os sujeitos estavam atravessando, como dificultadores para se colocarem disponíveis de fato para as vivências. Exemplos: "tive uma perda familiar recente", "as dificuldades vêm desde o tempo de academia".

Para os sujeitos que não manifestaram dificuldades, apreendemos duas categorias:

Identificação com o Grupo - remetem às sensações diante do grupo, ou seja o grupo como favorecedor do desempenho pessoal. Esta categoria está vinculada com a vivência grupal, descrita anteriormente. 
Exemplos: "o grupo aberto, sensivel", "os colegas amigos, me senti a vontade".

Estratégias de Ensino - englobam relatos sobre a forma como as dinâmicas foram oferecidas e realizadas, propiciando o desenvolvimento individual. Exemplos: "o respeito que fomos tratados", "ambiente propício e material adequado".

Diante da terceira questão, sobre as contribuições da oficina para a atuação do Ser Enfermeiro, emergiram como categorias:

Processo avaliativo - descrevem o momento como oportunidade de reflexão e análise, como forma de descobertas que propiciam o conhecimento, no que se refere à temática proposta. Exemplos: "fiz uma autoavaliação", "oportunidade para a pessoa se analisar".

Intensidade - refletem algumas tentativas de dimensionar as contribuições recebidas. Exemplos: "de grandes proporções", "contribuições imensuráveis".

Enfermeiro como Pessoa - sugerem a possibilidade de conexão do papel pessoal com o profissional. Esta categoria é uma repetição da primeira, identificada dentro das experiências significativas, parece que surge como reforço. Exemplos: "lembrei que sou um todo, sou um ser humano", "somos pessoas, seres humanos cheios de defeitos e qualidades, sentimentos dos mais variados, somos também enfermeiros".

Resultados - expõem de que forma as contribuições podem extrapolar no dia a dia do Ser enfermeiro no trabalho. Exemplos: "ajuda a ser mais humano e menos 'carrasco', "relacionar melhor com a equipe e com o cliente".

Os conteúdos da quarta questão, que buscava sugestões para outros cursos desta natureza, foram categorizadas como:

Significância da experiência - denotam a importância do processo vivenciado, congratulando o desempenho das coordenadoras e do tipo de trabalho proposto. Exemplos: "perfeito, criativo, lindo", "vocês estão de parabéns".

Continuidade - sugerem que o método de trabalho deve ser intensificado, ou seja que novas vivências possam ser propiciadas em outros eventos da categoria. Exemplos: "devem continuar com outras oficinas", "promover outros cursos como este".

Estruturação - relacionam alguns dados, no que se refere à reedição para outras vivências, tais como carga horária, local e número de vagas. Exemplos: "ampliar número de vagas", "mais tempo se faz necessário”.

\section{DISCUSSÃO DOS DADOS}

Investigando sobre a experiência mais significativa para cada participante, no decorrer da oficina, os conteúdos englobaram aspectos variados, tais como a visualização de uma integração do Ser profissional com o Ser pessoa, o valor do grupo para o desempenho da proposta, as técnicas como elementos facilitadores e o enriquecimento individual decorrente dos trabalhos.

As respostas desta primeira questão, destacam um dos objetivos da oficina, ou seja despertar a visualização da pessoa no profissional, além de valorizarem as estratégias utilizadas, as quais são expressas nas categorias vivência grupal e técnicas experienciadas.

A metodologia implementada foi alvo de atenção tanto pelos sujeitos que manifestaram dificuldades de expressão em algum momento dos trabalhos, quanto por aqueles que as negaram. As características individuais de cada pessoa também foram ressaltadas, ora como facilitadoras, ora dificultadoras no processo. Não é novidade que algumas pessoas se mostrem mais abertas a novas propostas de ensino e que outras, ao contrário, se sintam presas a modelos tradicionais.

Os recursos utilizados mereceram destaque na avaliação, pela informalidade que proporcionavam nas discussões, de aspectos relativos ao exercício profissional, muitas vezes impregnados de teores formais e polêmicos; as estratégias de ensino propostas, não convencionais no processo de aprendizagem, foram também enaltecidas pela maneira descontraída com que eram conduzidas, além de sempre virem acompanhadas de reflexões teórico-práticas pertinentes.

A enfermagem continua limitada no que se refere a propiciar e admitir novas abordagens de ensino. Segundo BRANT \& ANTUNES (1995) a ênfase no ensino de enfermagem, continua sendo a metodologia de transmissão de conhecimentos, onde o aluno é considerado uma página em branco, onde novos conhecimentos de origem externa serão imprimidos e aliada a esta, freqüentemente utilizamos a opção pedagógica denominada condicionamento, conhecida como conducionista ou tecnicista, onde o mais importante é fazer e não o saber. Estas concepções pedagógicas formam grupos sociais acríticos, passivos, dependentes e conformados.

Sobre as contribuições proporcionadas pela oficina, outra vez os participantes explicitaram um dos objetivos previamente estabelecido, ou seja a visualização do enfermeiro também como Ser humano, que exerce sua profissão, e não somente como um profissional, desprovido das características inerentes ao homem. Além deste, referendaram a importância do processo reflexivo, ocasionando uma avaliação do papel desenvolvido no dia a dia e também afirmaram a possibilidade deste processo ir além da experiência vivida, favorecendo mudanças na prática profissional. 
As mudanças geralmente não ocorrem a partir de experiência única vivida, mas a visualização de possíveis alterações no modo de ser é sem dúvida um fator inicial para que ela possa realmente ocorrer, fazendose necessário respeitar o processo de ver, perceber e introjetar, para não ficar estagnada na inércia.

A partir da solicitação de sugestões para novos trabalhos, evidenciamos que, por um lado, as pessoas não puderam contribuir concretamente com sugestões para mudanças a serem realizadas, mas reforçaram a importância deste tipo de trabalho. A intensidade e a continuidade, categorias apreendidas, nos direcionam ao entendimento de que devemos continuar valorizando e implementando estratégias problematizadoras, fugindo do ensino tradicional.

Não nos surpreende o fato dos sujeitos não extrapolarem as afirmações de que é ótimo e maravilhoso, porque acostumados a uma pedagogia predominantemente de condicionamento e tecnicista, ficam impossibilitados de exercerem uma visão crítica do processo experienciado.

GERMANO (1993), fazendo algumas considerações sobre a relação professor-aluno no processo ensino-aprendizagem da enfermagem, afirma que as pesquisas denunciam um ensino rígido, autoritário, eletista, acrítico, pouco criativo e essencialmente tecnicista.

Entendemos que o ensino direcionado à categoria de enfermagem, está imerso no sistema sócio-político e econômico do País e que nesse sentido nós docentes somos um reflexo da ideologia dominante. Porém, defendemos também, que o momento é oportuno para redirecionar nossas ações, no sentido de sermos formadores de sujeitos que possam participar do processo de transformação social e da enfermagem.

\section{COMENTÁRIOS FINAIS}

O estudo realizado enfatiza a importância das estratégias de ensino no processo de aprendizagem, aspecto este que pontuamos como fundamental no exercício da docência.

Os conteúdos das descrições dos sujeitos valorizam o tipo de trabalho que temos utilizado como recurso metodológico, o qual reforça a relação professor/ aluno e possibilita a formação de indivíduos mais críticos.

Constatamos também que o uso de estratégias de ensino não convencionais, como as vivências implementadas, propiciam a assimilação melhor do conteúdo programático, fato este observado pelo tipo de respostas emitidas pelos participantes.

Podemos questionar se as pessoas que procuraram este "curso" específico, dentre outros oferecidos no evento, são pessoas que previamente já conhecem e se interessam por este tipo de trabalho e por isso tenham apontado resultados positivos. Porém, nossas experiências nesta modalidade de prática de ensino tem nos mostrado semelhança nos relatos.

A concepção metodológica defendida neste trabalho, embora diferente daquela predominante no ensino da enfermagem, denota um caminho eficaz no sentido de ajudar na construção de indivíduos que possam participar efetivamente do momento de transformação social e profissional que estamos vivenciando.

\section{REVIEWING TEACHING STRATEGIES IN A LEARNING PROCESS}

This is a qualitative research that aimed at finding out opinions on the learning process that was used with the participants of the workshop "Learning what is to be a nurse", presented at the $47^{\circ}$ Brazilian Nursing Congress, in Goiania, in 1995, in order to analize the teaching strategies introduced during the workshop. Data were collected from an evaluation questionnaire that was answered by the participants who were the subjects of this research. We submitted the answers to a content analysis using a thematic categoryzation and identified classes which distinguish or sometimes emphasize the searched strategies.

KEY WORDS: learning, nursing

\section{REPENSANDO ESTRATEGIAS DE ENSEÑANZA EN EL PROCESO DE APRENDIZAJE}

Se trata de un estudio cualitativo, realizado en un taller cuyo nombre es "Conociendo el SER Enfermero", ofrecido en el $47^{\circ}$ Congreso Brasileño de Enfermería, en la ciudad de Goiânia en 1995, cuyo objetivo fue el de analizar las estrategias de enseñanza implementadas durante el taller, según los registros de los participantes. La recolección de datos se realizó a través de una ficha de evaluación, que fue respondida por los participantes del taller que fueron sometidos a los estudios. Fue hecho un análisis del contenido de las respuestas, utilizándose una categorizacion temática, donde identificamos las categorías que destacan las estrategias utilizadas 


\section{ANEXO 1}

\section{$47^{\circ}$ Congresso Brasileiro de Enfermagem \\ 19 - 24 de novembro de 1995 \\ Goiânia - GO \\ OFICINA DE VIVÊNCIA \\ CONHECENDO O SER ENFERMEIRO}

\section{FICHA DE AVALIAÇÃO}

1. Dentre o que você vivenciou nestes dois dias, qual a experiência mais significativa que teve? Por que?

2. Houve dificuldades para você se expressar em algum momento dos trabalhos? Comente-os.

3. Que contribuição um curso dessa natureza traz para a atuação do $\boldsymbol{S e r}$ enfermeiro?

4. Dê sugestões, pois elas são importantes para o nosso aprimoramento.

\section{REFERÊNCIAS BIBLIOGRÁFICAS}

01. ALMEIDA, M.do C.dos S. Tendências pedagógicas na formação do enfermeiro na Paraíba - João Pessoa. João Pessoa, 1992. Dissertação (mestrado) - Universidade Federal da Paraíba.

02. ANTUNES, C. Manual de técnicas de dinâmica de grupo de sensibilização de ludopedagogia. Rio de Janeiro: Vozes, 1995.

03. BARDIN, L. Análise de conteúdo. (L’Analyse de Contenu). Lisboa: Edições 70, 1977. 226 p.

04. BOCCHI, S.C.M.; PESSUTO, J.; DELL'AQUA, M.C.Q. Modelo operacional do estudo de caso como estratégia de ensino na disciplina de enfermagem médico-cirúrgica: avaliação dos alunos. Rev.latino-am.enfermagem, Ribeirão Preto, v. 4, n. 3, p. 99-115, dez./1996.

05. BRANT, M.J.C.G.C.; ANTUNES, M.J.M. Concepções pedagógicas: influência na educação e na prática da enfermagem. In: CONGRESSO BRASILEIRO DE ENFERMAGEM, 47, Goiânia, 1995. Sínteses. Goiânia: Centro Editorial e Gráfico UFG, 1995. p. 169-170.

06. CHAVES, E.C. O desempenho de papéis sociais numa relação de ensino-aprendizado. Rev.latinoam.enfermagem, Ribeirão Preto, v. 1, p. 35-42, dez/1993. $n^{\circ}$ especial.

07. GERMANO, R.M. Educação e ideologia da Enfermagem no Brasil. 3. ed. São Paulo: Cortez, 1993.

08. HADDAD, M.do C.L. et al. Enfermagem médicocirúrgica: uma nova abordagem de ensino e sua avaliação pelo aluno. Rev.latinoam.enfermagem, Ribeirão Preto, v. 2, p. 97-112, jul./1993.
09. IRVING, S. Enfermagem psiquiátrica básica. 2 . ed. Trad. Fernando Diniz Mundem e Maria Dolores Lins de Andrade. Rio de Janeiro: Interamericana, 1979.

10. ISAACS, L.G.de. El efecto de enseñar las destrezas del pensamiento crítico en un curso introductorio de enfermería. Rev.latino-am.enfermagem, Ribeirão Preto, v. 2, n. 2, p. 115-127, jan./1994.

11. LIBÂNEO, J.C. Democratização da escola pública: a pedagogia crítico-social dos conteúdos. São Paulo: Loyola, 1985.

12. Didática. São Paulo: Cortez, 1991.

13. MANZOLLI, M.C. Enfermagem psiquiátrica: da enfermagem psiquiátrica à saúde mental. São Paulo: Guanabara Koogan, 1996.

14. MIRANDA, S. Oficina de dinâmicas de grupos. Campinas: Papirus, 1996.

15. PEPLAU, H.E. Interpersonal relations in Nursing. Nova York: Putnam's, 1952.

16. TOREZAN, M.T. Processo ensino-aprendizagem: concepções reveladas por professores de $1^{\circ}$ grau na discussão de problemas educacionais. Psicologia: teoria e pesquisa, Brasília, v. 10, $\mathrm{n}$. 3, p. 383-391, set./dez. 1994.

17. TRAVELBEE, J. Intervención en Enfermería Psiquiátrica: el proceso da relación de persona a persona. Colômbia: OPAS/OMS, 1979.

18. VENDRÚSCOLO, D.M.S.; MANZOLLI, M.C. O currículo na e da enfermagem: por onde começar e recomeçar. Rev.latino-am.enfermagem, Ribeirão Preto, v. 4, n. 1, p. 55-70, jan.1996.

19. YOZO, R.Y.K. 100 jogos para grupos - uma abordagem psicodramática para empresas, escolas e clínicas. São Paulo: Ágora, 1996. 191p. 